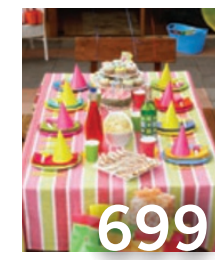

No celebration:

Parents use parties

as an alternative to

child vaccination
Genetic diversity:

Charles Rotimi leads a

new center focused on

health disparities

\title{
Harvard turns to matchmaking to speed translational research
}

Joan Brugge knew she had met her man during a 2006 meeting in a small, crowded conference room at the Dana-Farber Cancer Institute in Boston. Brugge, who heads the department of cell biology at Harvard Medical School, had just presented exciting findings: her group had identified a protein called BIM that acts as an 'executioner' of abnormally-proliferating cells. Crucially, in cells engineered to carry certain cancer-causing genes, the expression of the BIM protein is switched off, allowing the cells to multiply unchecked. "I really wanted to see whether BIM was being shut off in real human tumors," recalls Brugge.

That was when Stuart Schnitt, a world authority in breast cancer pathology at the Harvard-affiliated Beth Israel Deaconess Medical Center piped up. "Stuart said that he could get us samples [from patients] and suggested we meet the next week to discuss it," according to Brugge.

The rest, as they say, is history. Using Schnitt's samples, Brugge found that in about $50 \%$ of human breast tumors BIM expression is almost completely suppressed. Today, her group is conducting tests in mice to see whether a drug that blocks BIM's degradation will end up killing cancer cells, too.

In Harvard's far-flung system of hospitals, Brugge and Schnitt each wouldn't have known that the other existed had they not

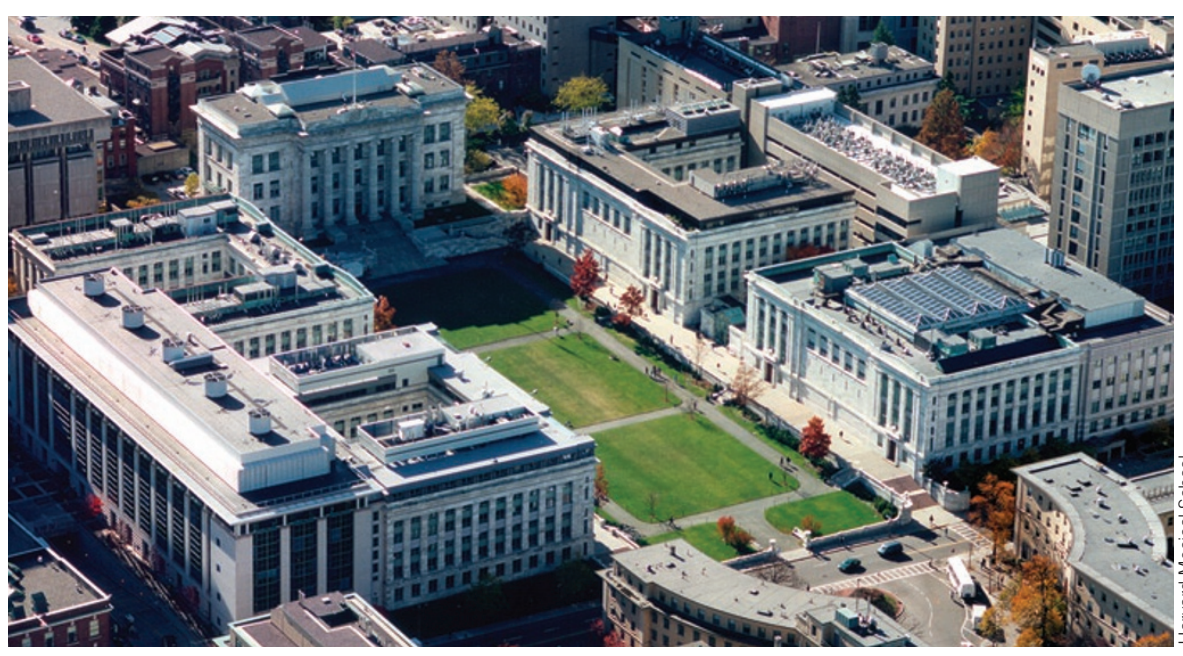

Taking the plunge: With new grants, researchers will pool their brainpower and resources both attended a series of meetings — including the fateful one in the crowded conference room-as participants in a special National Cancer Institute grant aimed at bringing basic scientists and clinicians together. But such grants are limited in both size and reach: they apply only to work in cancer and are worth

In late May, Harvard Medical School and its affiliated teaching hospitals_-including Beth Israel Deaconess-landed a grant nearly 60 times as large aimed at hooking up basic scientists and clinical researchers in an effort to more quickly turn lab-dish ideas into medicines and methods that will help patients. More specifically, they were awarded \$118 million over five years from the US National Institutes of Health (NIH) in the form of a 'clinical and translational science award', or CTSA.

The award is the largest among 38 made over the last two years as part of an ambitious effort by NIH Director Elias Zerhouni to bring scientists and clinicians together to push basic science more quickly into palpable benefits for patients. By 2012, NIH plans to be spending $\$ 500$ million annually on 60 such centers (see Nature 453, 840-842; 2008).

This kind of collaboration is far from standard practice in academia. But at Harvard in particular, it poses key challenges, including how to help potential collaborators about $\$ 2$ million.

find each other in a vast warren of researchers that includes millions of square feet of lab space and thousands of faculty. And uniquely at Harvard-whose independently-owned, highly-acclaimed hospitals have historically been fiercely competitive-it will require researchers accustomed to rivalry to begin seeing each other as teammates.

"The essence of our grant and the metric of success for us will be: can we get people in a room together on a project that never would have been there before?" says Lee Nadler, the codirector of the new Clinical and Translational Science Center created in May to help distribute the \$118 award.

\section{Making it happen}

In an era of frozen funding at NIH, Harvard is pulling out the stops to make the new project a success. It's instituting key administrative changes with the aim of allowing a patient in any one of its 18 affiliated hospitals to be enrolled in a clinical trial at any other hospital in the system. It is also hiring 'research navigators' charged with helping researchers find each other and coalesce to move a project forward. Scientists and clinicians will also be able to seek each other out through a 'matchmaking' service on a new internet portal.

Harvard and its hospitals are also putting cash on the line, augmenting the new NIH funding with an additional \$15 million annually.

But belief in this collaborative grant approach doesn't necessarily come easily. At Johns Hopkins University, which won a CTSA last year, "people are still a little tentative about buying into the big idea" of research teams that shepherd an idea from the lab to the clinic, says Dan Ford, the vice dean for clinical investigation, who runs Hopkins' new Institute for Clinical and Translational Research (ICTR).

"It requires a level of trust," says Ford. "Some of the steps you are not going to be able to do on your own. At some point you are going to have to believe that the institution believes in this concept."

Meredith Wadman, Washington, DC 